This article was downloaded by: [Lancaster University Library]

On: 18 April 2013, At: 07:01

Publisher: Routledge

Informa Ltd Registered in England and Wales Registered Number: 1072954 Registered office: Mortimer House, 37-41 Mortimer Street, London W1T 3J H, UK

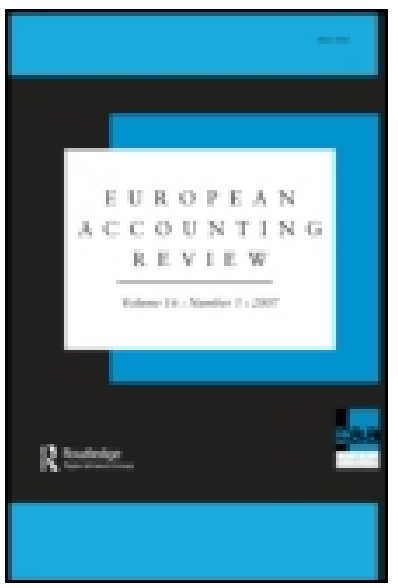

\title{
European Accounting Review
}

Publication details, including instructions for authors and subscription information:

http:/ / www. tandfonline.com/ loi/ rear20

\section{Residual Income Valuation Models and Inflation}

\author{
David Ashton ${ }^{a}$, Ken Peasnell ${ }^{b} \&$ Pengguo Wang ${ }^{a}$ \\ a Department of Accounting and Finance, Bristol \\ University, UK \\ b Lancaster University Management School, Lancaster, \\ UK \\ Version of record first published: 25 J un 2010.
}

To cite this article: David Ashton, Ken Peasnell \& Pengguo Wang (2011): Residual Income Valuation Models and Inflation, European Accounting Review, 20:3, 459-483

To link to this article: http:// dx. doi.org/ 10.1080/09638180.2010.493661

\section{PLEASE SCROLL DOWN FOR ARTICLE}

Full terms and conditions of use: http://www.tandfonline.com/page/termsand-conditions

This article may be used for research, teaching, and private study purposes. Any substantial or systematic reproduction, redistribution, reselling, loan, sublicensing, systematic supply, or distribution in any form to anyone is expressly forbidden.

The publisher does not give any warranty express or implied or make any representation that the contents will be complete or accurate or up to date. The accuracy of any instructions, formulae, and drug doses should be independently verified with primary sources. The publisher shall not be liable for any loss, actions, claims, proceedings, demand, or costs or damages whatsoever or howsoever caused arising directly or indirectly in connection with or arising out of the use of this material. 


\title{
Residual Income Valuation Models and Inflation
}

\author{
DAVID ASHTON*, KEN PEASNELL** and PENGGUO WANG* \\ ${ }^{*}$ Department of Accounting and Finance, Bristol University, UK and ${ }^{* *}$ Lancaster University \\ Management School, Lancaster, UK
}

(Received: August 2009; accepted May 2010)

AbSTRACT Existing empirical evidence suggests that residual income valuation models based on historical cost accounting considerably underestimate equity values. One possible explanation is the use of historical cost accounting under inflationary conditions. In this paper, we use a residual income framework to explore theoretically how historical cost accounting numbers need to be adjusted for inflation in forecasting and valuation. We demonstrate that even in a simple setting where inflation is running at a relatively low level, residual income models are likely to produce severe undervaluations if inflation is not properly taken into account. We use simulated data to reinforce our theoretical findings and to illustrate the difficulties that empirical investigators face working within the confines imposed by real data.

\section{Introduction}

Existing literature documents that the residual income valuation model (RIVM) considerably underestimates equity shares (Choi et al., 2005; Dechow et al., 1998; Myers, 1999). One possible explanation is that the primary inputs of the model, book value of equity and earnings, are distorted by conservative accounting policies such as: historical cost accounting rules, over depreciation of assets, expensing of $\mathrm{R} \& \mathrm{D}$, no recognition of internally generated goodwill, or the delayed recognition of 'good news' (Feltham and Ohlson, 1995; Watts, 2003a, 2003b). All of these forms of conservatism potentially drive a wedge between book and market values. In this paper, we focus on the impact of just one of these forms of conservatism, one that is inherent in historical cost accounting

Correspondence Address: David Ashton, Department of Accounting and Finance, Bristol University, Bristol BS8 1TN, UK. Email: david.ashton@bristol.ac.uk 
under inflationary conditions, where conservatism stems from the failure to recognize holding gains ${ }^{1}$ in the reporting of assets.

There is substantial evidence - at least in countries with low (but persistent) rates of inflation - that investors tend to ignore inflation, assuming it is of second-order importance, or are confused as to its impact (Feyr and Tyran, 2001; Modigliani and Cohn, 1979; Ritter and Warr, 2002). These difficulties arise because inflation affects historical cost accounting numbers in complex ways, leading to difficulties in establishing the relationship between reported accounting numbers and equity valuation. We use a residual income model to explore this relationship between market price, book assets and reported earnings under inflationary conditions. Residual income valuation models form an ideal vehicle for such an exploration, because under plausible assumptions they generate a linear form for the relationship between market prices, reported asset values and earnings.

The undervaluation observed by empirical researchers using data extracted from financial statements has led others to adjust the accounting inputs into RIVM for inflation (Gregory et al., 2005; Ritter and Warr, 2002). Gregory et al. (2005) find that the persistence parameter of abnormal earnings using historical cost reported data is statistically indistinguishable from the persistence parameter of abnormal earnings that uses accounting data adjusted for inflation. An implication of this observation is that, under the assumption of a simple autoregressive process for residual income, the present value of residual income is unlikely to bridge the shortfall between historical cost and current cost book values. Our model confirms this result and provides a demonstration of how, even in the simplest setting, relatively low rates of inflation can make a substantial difference to asset valuation. It also provides insights into ways to restructure residual income valuation models to take account of the distortions introduced by the use of historical cost accounting.

Hughes et al. (2004) examine the value relevance of accounting variables and characterize the impact of inflation and foreign exchange on the weights that attach to the accounting items. However, they are primarily concerned with the question as to whether one can adjust depreciation policy in an inflationary environment to produce an unbiased valuation model. Our focus is on the empirical distortions produced by inflation when using reported book values. We explore to what extent model value is underestimated when inflation is ignored, and how to adjust inflation when forecasting (abnormal) earnings and valuing equity while implementing RIVM. We emphasize how inflation changes the structure of abnormal earnings information dynamics from that hypothesized in unbiased accounting. This distortion results in the addition of inflation-adjusted book value terms on the right-hand side of the simple autoregressive process describing the evolution of current cost abnormal earnings. We deliberately keep our model simple in order to generate closed form solutions and hence sharpen the insights from our analysis. In contrast to the mean reverting process of Hughes et al. (2004), we assume a constant rate of inflation to produce an equilibrium solution 
independent of time. However, even in this intentionally simple and unrealistic setting, in order to generate our closed form solution, we need to make a number of approximations in the theoretical development.

Under clean surplus accounting, O'Hanlon and Peasnell (2005) show theoretically that, provided internally consistent definitions are used, it matters little whether the accounting system used in residual income valuation models is based on historical cost accounting conventions or on figures adjusted for inflation. This equivalence has important implications. Although book value and earnings are distorted by inflation in particular, and by conservatism in general, equity values derived from RIVM should be the same as those from DDM. This implies that if equity share prices fluctuate around their intrinsic values provided by the DDM in an efficient capital market, the same must apply to the RIVM. Therefore, underestimation when using the RIVM can be due either to an inappropriate implementation of the model or to equity being mispriced.

The benchmark against which all empirical valuation models are measured is the observed market price sampled at a time when it is assumed that the relevant accounting information is available. Since we are focusing on just one aspect of accounting policies that drives a wedge between market and book values, we create a controlled environment against which to measure the performance of our theoretical models. To do this, we simulate and then sample from 500 years of data facilitating a numerical check on the accuracy of the approximations made in developing our theoretical model.

A further problem that arises in the implementation of RIVM models is the necessity to specify a horizon value by reference to an assumed growth in perpetuity. This growth is normally approximated by a real risk free rate or the rate of inflation (Claus and Thomas, 2001; Ohlson and Juettner-Nauroth, 2002). In contrast, existing theoretical models assume that an unbiased measure of residual income will follow a simple dampening autoregressive process, with an implied negative growth rate, to reflect the expected erosion of economic rents through the forces of market competition (Ohlson, 1995). ${ }^{2}$ A legitimate question to ask, one that we explore here, is how this unbiased measure of residual income can be distorted by inflation and what the appropriate growth rate should be in terminal valuations.

When establishing the theoretical relationship between the residual income information dynamics of reported data and inflation-adjusted data, we find that inflation-adjusted accruals incorporate a representation of the complete history of a firm's accounting results. We use our simulation model to identify the appropriate number of lags to use in a robust approximation. The simulation approach provides us with two further advantages. First, by providing us with long stable time series for analysis, it overcomes the problem of the uncertainty in parameter estimation that is inherent with short sample periods for analysing the time-series dynamics of abnormal earnings (Myers, 1999). Second, the simulation approach provides a test of the numerical validity of alternative model structures and approaches to valuation, using both historical cost accounting data and inflation-adjusted accounting data. 
We show theoretically, and confirm with simulated data, that valuation weights on book value and dividends increase with inflation, whilst those on earnings decrease with inflation. Thus, consistent with our intuition, the multiplier on book value increases to compensate for understatement of book value when inflation is higher or accounting is more conservative. However, we note that confidence intervals are sufficiently large in the controlled environment of our simulations as not to bode well for empirical investigators working within the confines imposed by real data.

The rest of the paper is set out as follows. Section 2 establishes the relationship between historical cost accounting and current cost accounting variables. This enables us to identify the valuation weights and the structure of the information dynamics describing the evolution of residual income in these two accounting systems. In Section 3, we develop a simulation model based on the notion that the firm's investment policy determines the pattern of growth over time. The simulation model provides insights into, and tests of, appropriate approximations in numerical computations of equity values. Section 4 links our simulation results with our theoretical model on the effects of inflation on information dynamics and valuation. Section 5 concludes the paper.

\section{Accounting, Linear Information Dynamics and Valuation}

In this section, we present our basic accounting model, both in the absence of, and in the presence of, inflation as captured by current cost (inflation-adjusted) accounting and historical cost accounting systems.

\subsection{Historical Cost Accounting and Current Cost Accounting}

Our accounting focuses on two triples needed for residual income-based valuation. The first, $\left\{b_{t}^{h c}, x_{t}^{h c}, d_{t}\right\}$, represents the historical cost book value of equity, residual income and dividends, respectively, at time $t$; and the second, $\left\{b_{t}^{c c}, x_{t}^{c c}, d_{t}\right\}$, represents inflation-adjusted (current cost) book value of equity, residual income and dividends, respectively, at time $t$. Associated accounting triples are $\left\{b_{t}^{h c}, e_{t}^{h c}, d_{t}\right\}$ and $\left\{b_{t}^{c c}, e_{t}^{c c}, d_{t}\right\}$, where in addition $e_{t}^{h c}$ and $e_{t}^{c c}$ represent, respectively, historical cost and inflation-adjusted earnings at time $t$. We assume clean surplus accounting (CSR) throughout the paper. ${ }^{3}$

We also specify value-relevant information in terms of a cash triple, $\left\{Y_{t}, I_{t}, d_{t}\right\}$, where $Y_{t}$ is the (net) cash inflow from operations and $I_{t}$ is the investment cash flow in time period $t$. On the assumption that the firm neither borrows nor invests in financial assets, these triples are linked by a cash balance equation, $Y_{t}=I_{t}+d_{t}$. We further assume that cash inflows from investments decline exponentially at a rate $\alpha(0<\alpha<1)$ and that depreciation is measured on a declining-balance basis. This rate is such that accounting depreciation is identical to economic depreciation, thereby resulting in unbiased accounting in the absence of inflation. The relevant historical cost accounts and cash flows are connected by 
the following system of accounting identities:

$$
b_{t+1}^{h c}=(1-\alpha) b_{t}^{h c}+I_{t+1}
$$

CSR, the cash balance equation and equation (1) together imply that

$$
e_{t+1}^{h c}=Y_{t+1}-I_{t+1}+b_{t+1}^{h c}-b_{t}^{h c}=Y_{t+1}-\alpha b_{t}^{h c}
$$

The corresponding residual income is defined as: $x_{t+1}^{h c} \equiv e_{t+1}^{h c}-i b_{t}^{h c}=$ $Y_{t+1}-(\alpha+i) b_{t}^{h c}$, where $i$ is the nominal cost of equity capital.

The cash flow and inflation-adjusted accounting numbers, on the other hand, are linked as follows:

$$
b_{t+1}^{c c}=(1-\alpha)(1+\eta) b_{t}^{c c}+I_{t+1}
$$

CSR, the cash balance equation and equation (2) together imply that

$$
e_{t+1}^{c c}=Y_{t+1}-I_{t+1}+b_{t+1}^{c c}-b_{t}^{c c}=Y_{t+1}-\alpha(1+\eta) b_{t}^{c c}+\eta b_{t}^{c c}
$$

The corresponding residual income is:

$$
x_{t+1}^{c c} \equiv e_{t+1}^{c c}-i b_{t}^{c c}=Y_{t+1}-(\alpha+r)(1+\eta) b_{t}^{c c},
$$

where $r$ is the real cost of equity capital and $\eta$ is the rate of inflation. ${ }^{4}$ In calculating earnings (comprehensive income) adjusted for inflation we have to recognise both the increased depreciation charge, $\alpha(1+\eta) b_{t}^{c c}$, and the holding gains on assets, $\eta b_{t}^{c c}$, over the period. The nominal cost of capital, $i$, is related to the real cost of capital, $r$, by the conventional Fisher relationship: $1+i=(1+r)(1+\eta)$. Here $r$ incorporates a real risk free return plus an equity risk premium.

\subsection{Historical Cost Accounting, Current Cost Accounting and Information Dynamics}

Following Ohlson (1995), we assume that the expectation at time $t$ of inflationadjusted residual income can be represented as a simple autoregressive process to reflect the expected eventual elimination of economic rents, i.e.

$$
E_{t}\left[x_{t+1}^{c c}\right]=\omega x_{t}^{c c}
$$

where $0<\omega<1$.

From equations (1) and (2) via cash flows $\left(Y_{t+1}\right)$ and investment $\left(I_{t+1}\right)$, we can derive the corresponding time-series relationship under historical cost reporting 
conventions:

$$
\begin{aligned}
& E_{t}\left[x_{t+1}^{h c}\right]+(\alpha+i) b_{t}^{h c}-(\alpha+r)(1+\eta) b_{t}^{c c} \\
& \quad=\omega\left(x_{t}^{h c}+(\alpha+i) b_{t-1}^{h c}-(\alpha+r)(1+\eta) b_{t-1}^{c c}\right)
\end{aligned}
$$

Again, using equations (1) and (2), $b_{t}^{c c}$ can be expressed in terms of $b_{t}^{h c}$ and a lag operator $L$ such that

$$
b_{t}^{c c}=[1-(1-\alpha)(1+\eta) L]^{-1}[1-(1-\alpha) L] b_{t}^{h c}
$$

where $L b_{t}=b_{t-1}, L^{2} b_{t}=b_{t-2}$, and so on. Equation (4) then can be reorganized as

$$
\begin{aligned}
E_{t}\left[x_{t+1}^{h c}\right]= & \omega x_{t}^{h c}-\eta(1-\alpha)[1-(1-\alpha)(1+\eta) L]^{-1}[1-(1+i) L] \\
& {\left[b_{t}^{h c}-\omega b_{t-1}^{h c}\right] }
\end{aligned}
$$

While we observe that the value of the persistence parameter, $\omega$, is preserved under historical cost reporting (Gregory et al., 2005), the conventional first-order autoregressive linear dynamics of historical cost abnormal earnings has to be modified (in principle at least) to include an infinity of lags of the book value term. ${ }^{5}$ Consistent with Beaver and Ryan (2005), equation (5) implies that we must include a complete history of book values in the information dynamics of abnormal earnings. We show in the appendix that there is no distortion of the linear information dynamics of abnormal earnings under inflationary conditions if the accounting data are adjusted for inflation. We shall return to this issue once we have achieved a greater understanding of the apparently complex relationship defined by equation (5) between historical cost accounting information and inflation-adjusted accounting information.

\subsection{Long-run properties of information dynamics}

Note that equations (1) and (2) relate reported book value and inflation-adjusted book value to investment. We can solve these equations to express book value at time $t$ as functions of prior investments:

$$
E\left[b_{t}^{h c}\right]=\frac{(1+\eta)^{t+1}}{\alpha+\eta}\left[1-\frac{(1-\alpha)^{t}}{(1+\eta)^{t}}\right] I_{0}
$$

and

$$
E\left[b_{t}^{c c}\right]=\frac{(1+\eta)^{t}}{\alpha}\left[1-(1-\alpha)^{t}\right] I_{0}
$$

where $\mathrm{E}[\tilde{I}]=I_{0}$. If we consider the long run equilibrium solutions to these equations, after the influence of the initial start-up values of the firm has been lost, we can express the ratio of inflation-adjusted book value to historical cost 
book value as

$$
\lim _{j \rightarrow \infty} E_{t}\left[b_{t+j}^{c c}\right] / E_{t}\left[b_{t+j}^{h c}\right]=\frac{\alpha+\eta}{\alpha(1+\eta)}
$$

It follows from equations (6) and (7) that, asymptotically, the expectations of $b_{t}^{c c}$ and $b_{t}^{h c}$ should both grow in line with inflation. Thus we have:

$$
\lim _{j \rightarrow \infty} E_{t}\left[b_{t+j+1}^{c c}\right] / E_{t}\left[b_{t+j}^{c c}\right]=1+\eta
$$

and

$$
\lim _{j \rightarrow \infty} E_{t}\left[b_{t+j+1}^{h c}\right] / E_{t}\left[b_{t+j}^{h c}\right]=1+\eta
$$

We can derive an asymptotic historical cost counterpart of the posited simple autoregressive linear dynamics equation for inflation-adjusted abnormal earnings, posited in equation (3). Using equations (1), (2) and (3) plus the asymptotic result in equations (8) and (9), we obtain:

$$
E_{t}\left[x_{t+1}^{h c}\right]=\omega x_{t}^{h c}+\frac{\eta r(1-\alpha)}{\alpha}\left(1-\frac{\omega}{(1+\eta)}\right) b_{t}^{h c}
$$

This structure is similar to that developed by Feltham and Ohlson $(1995,1996)$ in their exploration of the impact of an over-cautious depreciation policy on linear dynamics. They suggest that this form of conservatism manifests itself in the associated LID as in equation (11):

$$
x_{t+1}^{h c}=\omega_{1} x_{t}^{h c}+\omega_{2} b_{t}^{h c}+\varepsilon_{x t+1} .
$$

In our case, conservatism arises in the delayed recognition of asset values and income under inflationary conditions and the coefficient of lagged book value assumes the parametric form, $\omega_{2}=\frac{\eta r(1-\alpha)}{\alpha}\left(1-\frac{\omega}{(1+\eta)}\right)$.

The structure of equation (10) enables us to explore theoretically, and later numerically, a question that we posed in the introduction as to what is the theoretically correct long run growth rate for abnormal earnings to be used in terminal valuation approximations of residual income. From equation (10) we can deduce that

$$
E_{t}\left[x_{t+j}^{h c}\right]=\omega^{s} x_{t}^{h c}+\frac{\eta r(1-\alpha)}{\alpha}\left(1-\frac{\omega}{(1+\eta)}\right)\left(\frac{\omega^{j}(1+\eta)^{j}-1}{\omega(1+\eta)-1}\right) b_{t}^{h c}
$$

As, by assumption, $0 \leq \omega \leq \omega(1+\eta)<1$, we have the asymptotic result:

$$
\lim _{j \rightarrow \infty} E_{t}\left[x_{t+j+1}^{h c}\right] / E_{t}\left[x_{t+j}^{h c}\right]=1+\eta
$$

Hence, in the long run, residual income grows at the rate of inflation. It should be remembered though, that in our analysis we have assumed that the real growth in 
investment is zero. In practice, this is likely to be positive and at an aggregate level perhaps the real growth rate in GDP should be added to this figure to produce a more realistic estimate of long-run growth. This observation could possibly account for the relatively low estimate for the equity risk premium that emerges for the work of Claus and Thomas (2001). However, we shall see in the next section that in residual income models the pivotal role is played by book value and not abnormal earnings.

\subsection{Closed Form Valuation Models}

RIVM establishes that under clean surplus accounting the difference between market price and book equity is equal to the present value of abnormal earnings. Assuming that the linear dynamics corresponds to equation (3), Ohlson (1995) shows that the valuation model reduces to the simple form $V_{t}=b_{t}+\frac{\omega}{R-\omega} x_{t}$, where $R$ is one plus the nominal cost of capital. We have argued that this form is only valid under inflationary conditions if asset values and abnormal earnings correctly reflect the impact of inflation. If we were to use unadjusted reported earnings then we need to rewrite the model as:

$$
\begin{aligned}
V_{t}= & b_{t}^{h c}+\frac{\omega}{1+i-\omega} x_{t}^{h c}+\left\{[1-(1-\alpha)(1+\eta) L]^{-1}[1-(1-\alpha) L]-1\right\} \frac{1+i}{1+i-\omega} b_{t}^{h c} \\
& +\frac{\omega}{1+i-\omega}\left\{(1+i)-(1+i-\eta)[1-(1-\alpha)(1+\eta) L]^{-1}[1-(1-\alpha) L]\right\} b_{t-1}^{h c} .
\end{aligned}
$$

We are again faced with the problem that the valuation of the firm requires a complete history of the firm and its investment. Theory suggests that the appropriate form of the linear information dynamics under inflation and historical cost reporting ought to include a lagged book value. However, the existence of a book-value term in the information dynamics of abnormal earnings equation (10) adds complications in equity valuation relative to that of a one-dimensional autoregressive process. This requires an understanding (or model) as to how book values evolve over time. Nevertheless, under plausible assumptions, we can develop a closed form for the valuation model. We will adopt two different approaches, one in which we will use a univariate time series model of the evolution of book-values, the other in which we will try to identify a dividend policy, which will determine retentions and hence the evolution of book values. We will then again use our simulation model to test the robustness of the two approaches.

First, we follow Feltham and Ohlson (1995) and assume an expected uniform growth in book values. In our case, for ease of exposition, ${ }^{6}$ we will initially assume that all historical cost growth is purely inflationary:

$$
E_{t}\left[b_{t+1}^{h c}\right]=(1+\eta) b_{t}^{h c}
$$


This together with equation (10) gives the following theoretical approximation for the value of equity:

$$
\begin{aligned}
V_{t}= & \left(1+\frac{\eta(1+r)(1-\alpha)(1+\eta-\omega)}{\alpha(1+\eta)[(1+r)(1+\eta)-\omega]}\right) b_{t}^{h c} \\
& +\left(\frac{\omega}{(1+r)(1+\eta)-\omega}\right) x_{t}^{h c}
\end{aligned}
$$

The difference between $V_{t}$ and the standard Ohlson (1995) valuation formulation is given by the additional inflation-adjusted book value expression in the first term on the right-hand side of equation (15). When $\eta=0, V_{t}$ reduces to the standard formulation. Moreover, this adjustment is a positive increasing function of inflation $\eta$ for given $0<\alpha, \omega<1$. Since $(1+r)(1+\eta)=1+i$, equation (15) also shows that the structure of the multiplier for historical cost accounting abnormal earnings is effectively unaltered by inflation, although clearly the value of the multiplier attached to earnings decreases in inflation due to the higher nominal cost of capital. Thus, equation (15) again draws attention to the pivotal role of the standard Ohlson residual income valuation framework: book value provides the 'first cut' at valuation, the present value of residual incomes being an adjustment to incorporate the 'goodwill' omitted from the balance sheet. This goodwill will include intangible assets and economic rents, together with any misstatements of the economic value of recorded assets. Such misstatements can be large in inflationary conditions, particularly for firms with substantial amounts of long-lived assets (i.e. where $\alpha$ is small).

Another way of understanding the effects of inflation is to rewrite equation (15) as a weighted average of book value and earnings. Applying clean surplus accounting, equation (15) can be rewritten as:

$$
V_{t}=(1-k) b_{t}^{h c}+k\left(\varphi e_{t}^{h c}-d_{t}\right)
$$

where

$$
\begin{aligned}
k & =i \theta-(1+i) \psi \\
\varphi & =\frac{(1+i)(\theta-\psi)}{i \theta-(1+i) \psi} \\
\theta & =\frac{\omega}{(1+i-\omega)} \\
\psi & =\frac{\eta(1-\alpha)}{\alpha(1+\eta)} \frac{(1+\eta-\omega)}{(1+i-\omega)}
\end{aligned}
$$

Here, the $\psi$ term represents the inflation adjustment to the convex valuation model of Ohlson (1995). Provided $\eta \geq 0$ and the rate of depreciation falls within a reasonable range, such as $0<\alpha<1-\omega /(1+r)$, it can be shown 
that the valuation weight attached to book value, 1-k, in equation (16) increases with inflation, while the valuation weight attached to earnings, $k \varphi$, in equation (16), decreases with inflation.

In practice, the assumption of uniform inflation over the life of the assets is merely a convenient way of generating a closed form parameterized valuation model. It fails to provide a satisfactory empirical method where such parameters are not easily observable. A possible alternative approach to the assumption of uniform growth in book values is to identify the dividend policy so that we can map out the evolution of retentions and hence book values over time. We shall adopt this approach with our simulated data primarily to see whether such a method might offer a viable alternative. The easiest and most obvious solution to the dividend policy issue is to invoke a Lintnerian dividend policy as follows:

$$
d_{t+1}=\delta d_{t}+\gamma e_{t+1}^{h c}+\varepsilon_{d, t+1}=\delta d_{t}+\gamma\left(x_{t+1}^{h c}+i b_{t}^{h c}\right)+\varepsilon_{d, t+1}
$$

where $\delta$ and $\gamma$, are constants, and $\varepsilon_{d, t+1}$ is a mean-zero error term. The identification of the parameters $\omega_{1}, \omega_{2}$ of equation (11) and $\delta$ and $\gamma$ of equation (17), together with the clean surplus accounting identity establishes the following three-dimensional vector autoregressive information structure: ${ }^{7}$

$$
E_{t}\left[\mathbf{z}_{t+1}^{h c}\right]=\boldsymbol{\Omega} \mathbf{z}_{t}^{h c}
$$

where

$$
\mathbf{z}_{t}^{h c}=\left(\begin{array}{c}
d_{t} \\
x_{t}^{h c} \\
b_{t}^{h c}
\end{array}\right), \boldsymbol{\Omega}=\left[\begin{array}{ccc}
\delta & \gamma \omega_{1} & \gamma\left(\omega_{2}+i\right) \\
0 & \omega_{1} & \omega_{2} \\
-\delta & (1-\gamma) \omega_{1} & (1-\gamma)\left(1+i+\omega_{2}\right)+\gamma
\end{array}\right]
$$

The residual income valuation model then implies that

$$
V_{t}=b_{t}^{h c}+\sum_{\tau=1}^{\infty}(1+i)^{-\tau} E_{t}\left[x_{t+\tau}^{h c}\right]=b_{t}^{h c}+(0,1,0)[(1+i) \mathbf{I}-\mathbf{\Omega}]^{-1} \mathbf{\Omega z}_{t}^{h c}
$$

where $\mathbf{I}$ is the identity matrix. By examining the sizes of the numerical errors in the valuation models developed in this paper, as represented by equations (15), (16) and (19), and then comparing these to the present value of the dividend stream over a long time horizon, in our case a 500-period horizon, we may gain some insight into the robustness of the various valuation approaches. In order achieve this, we develop a simulation model in which we test the approaches outlined to valuation and contrast these with the results of simply using the Ohlson model and historical accounting variables unadjusted for inflation. 


\section{Description of Simulation Model}

In order to gain insight into both the accuracy of our numerical approximations and to explore some of the practical issues surrounding empirical estimation procedures, we replicate the above basic model using Monte Carlo simulation. We are trying to understand the relationship between two different reporting systems, one based on historical cost accounting, one on inflation adjusted accounting. Of course, these are just different ways of reporting the same cash transactions. The treatment of cash items in the presence of uniform inflation is well understood. Hence, as in Beaver and Ryan (2005), we use the investment policy to determine the growth over time. We assume that total nominal investment, which includes both replacement investment and new investment, grows at the same rate as inflation and $I_{t}=\tilde{I}(1+\eta)^{t}$, where $\tilde{I}$ is a random variable, which for simulation purposes is assumed to follow a uniform distribution on the interval $[0.25,0.75]$. The cash inflow from operations is related to the cumulative investment to date assuming a normal distribution for the return of equity. The stochastic growth in investment together with the random cash returns on investment induces a corresponding stochastic growth in the book values, whichever accounting method is used for the computation of book values. This ensures that book values and investment in the long run grow stochastically in line with inflation. This structure creates the growth structure in book values assumed in the theoretical model. In the absence of inflation, the expected level of investment for the firm is constant; nominal growth in investment is wholly attributable to inflation.

First, we construct a set of accounts, $\left\{e_{t}^{c c}, b_{t}^{c c}, d_{t}, x_{t}^{c c}\right\}$, using inflation-adjusted accounting conventions, and then a parallel set of accounts from the same underlying set of cash transactions $\left(Y_{t}, I_{t}\right)$, using historical cost accounting, $\left\{e_{t}^{h c}, b_{t}^{h c}, d_{t}, x_{t}^{h c}\right\}$. Starting from inflation-adjusted accounting, book values $\left(b_{t}^{c c}\right)$ in successive periods are linked as in equation (2), with the beginning book value initialized at $b_{0}=1$ and assuming a specific rate of depreciation and inflation. In order to obtain the simulated earnings numbers adjusted for inflation, we assume residual income is generated according to the following process:

$$
x_{t+1}^{c c}=\omega x_{t}^{c c}+i b_{t}^{c c} \tilde{\varepsilon} \text { where } \tilde{\varepsilon} \sim N(0, \sigma)
$$

where $N($.$) is the cumulative normal distribution we use for simulation purposes.$ Thus, earnings $e_{t+1}^{c c}=x_{t+1}^{c c}+i b_{t}^{c c}$.

Equation (20) implies that the accounting rate of return on equity effectively follows a mean-reverting process with mean equal to the cost of equity capital and with a standard deviation of $i \sigma$. Equations (2) and (20) taken together identify cash flows from operations $\left(Y_{t}\right)$ and describe the evolution of investment, book equity and earnings. We compute dividends as the residual in this process, $d_{t}=Y_{t}-I_{t}$. Hence we identify the set $\left\{e_{t}^{c c}, b_{t}^{c c}, d_{t}, x_{t}^{c c}\right\}$, where the accounting for earnings and book value reflects inflation. From the inflation-adjusted 
information set we extract the implied cash flows $\left(Y_{t}, I_{t}\right)$ and construct a parallel set of historical cost accounts, $\left\{e_{t}^{h c}, b_{t}^{h c}, d_{t}, x_{t}^{h c}\right\}$ by using equation (1) and the clean surplus restriction.

To initialize the process, we run each individual simulation for 50 time periods and then estimate all our parameters over the next 30 year period. ${ }^{8}$ We then use a variety of valuation models to estimate the equity value at the end of each estimation period. We calculate the 'true' market price of the equity by computing the present value of the dividend stream up to a 500-period horizon.

We set the real cost of capital, ${ }^{9} r$, at $6.6 \%$. This real cost of capital combined with assumed mean inflation rates of between $0 \%$ and $9 \%$, although allowing a small inter-period fluctuation around each mean of about $0.5 \%$ p.a., results in a nominal cost of capital between $6.6 \%$ and $16.2 \%$. We set the parameter $\sigma$, which determines the variation in residual income at 0.33 . The value of $\sigma$ was set such that the standard deviation of return on equity was about $40 \%$ of the return on equity. This roughly corresponds to that observed in medium-sized US firms. Prior to generating the results reported in this paper we set $\sigma$ at a very low value to check that the simulation was producing values in line with those theoretically predicted. In all the reported runs, we keep the autoregressive parameter $\omega$ at 0.6 . These parameter values are consistent with most of the prior literature (Choi et al., 2005; Dechow et al., 1998; Gregory et al., 2005). We find that variation in these parameters or the noise makes little impact on the nature of the results and hence details of these are not reported.

Our experimentation with the model consists of exploring the interaction between depreciation rates, inflation and valuation. Hence, we vary the rate of depreciation between $5 \%$ and $25 \%$ in steps of $5 \%$ and the inflation rate between $0 \%$ and $9 \%$ in steps of $1 \%$. Each run that we report is the average of 250 independent simulations of estimates based on 30 consecutive data points with all parameters other than random noise terms in the residual income generation and investment process fixed.

\section{Simulation, Information Dynamics and Valuation}

\subsection{Simulated Information Dynamics and Inflation}

Although our principal focus is the potential impact on valuation, we start by exploring how inflation affects the linear information dynamics. Our theoretical model, equation (5), suggests that neither the value of the persistence parameter $(\omega)$ nor the number of lags of abnormal earnings are affected by the use of historical cost accounting in an inflationary environment. However, our theoretical model suggests that there is infinity of lags in the book value term. Motivated by the theoretical specification of equation (5), we explore both these issues. For each of the 250 independent simulations, we carry out simple ordinary leastsquares (OLS) and scaled (by opening book value) OLS regressions of residual income on lagged residual income and book values at different rates of inflation 
using the historical cost data generated over the periods $t=51$ to 80 . We then compute the average value of the regression coefficients and the $t$-statistics.

Table 1 illustrates the nature of our results showing average values obtained under historical cost measurement conventions over inflation rates of $2 \%, 3 \%$, $4 \%$ and $5 \%$, with declining balance depreciation set at $15 \%$ per annum. We observe in Table 1 that the coefficient of lagged residual income is indeed not significantly changed by the use of historical cost measures. On the other hand, the coefficient of lagged book value is significant at lag one only, and adding higher lags to book value destroys the significance. Further simulations using higher rates of inflation and different lagged structures confirms the generality of this structure, both for historical cost and inflation-adjusted data. We attribute this to the high degree of correlation between successive book value terms. ${ }^{10}$

Table 1. The structure of the linear information dynamics

\begin{tabular}{lccc}
\hline Coefficient & Model 1 & Model 2 & Model 3 \\
\hline$\omega_{1}$ & 0.57 & 0.57 & 0.49 \\
(t-value-difference from 0.6) & $(-0.39)$ & $(-0.34)$ & $(-1.29)$ \\
$\omega_{2}$ & & 0.01 & -0.03 \\
$(\mathrm{t}-$ value) & & $(1.92)$ & $(-0.02)$ \\
$\omega_{3}$ & & & -0.04 \\
$(\mathrm{t}-$ value $)$ & $34.2 \%$ & $39.0 \%$ & $(0.22)$ \\
$R^{2}$ & & & $41.3 \%$ \\
\hline
\end{tabular}

The table shows the average values of the coefficients, together with average $t$-values for the three models. The $t$-value for $\omega_{1}$ measures the significance of the difference from the input value of 0.6. The remaining $t$-values measure the significance of the difference from zero. The averages are computed over inflation rates of $3 \%, 4 \%$ and $5 \%$ all at an assumed depreciation rate of $15 \%$.

Model 1: $x_{t+1}^{h c}=\omega_{1} x_{t}^{h c}+\varepsilon_{t+1}$

Model 2: $x_{t+1}^{h c}=\omega_{1} x_{t}^{h c}+\omega_{2} b_{t}^{h c}+\varepsilon_{t+1}$

Model 3: $x_{t+1}^{h c}=\omega_{1} x_{t}^{h c}+\omega_{2} b_{t}^{h c}+\omega_{3} b_{t-1}^{h c}+\varepsilon_{t+1}$

We thus choose to explore in more detail the restricted model equation (21) with only a single lag in both book value and residual income:

$$
x_{t+1}^{h c}=\omega_{1} x_{t}^{h c}+\omega_{2} b_{t}^{h c}+\varepsilon_{x t+1},
$$

where $\omega_{1}$ and $\omega_{2}$ are constants, and $\varepsilon_{x, t+1}$ is an unpredictable mean-zero error term. Equation (10), of course, provides theoretical support for the observation in the simulation output that a single-period lagged book value term is important in forecasting abnormal earnings in an inflationary economic environment. Put another way, the simulation also provides a justification for the approximations made in deriving the theoretical values and confirms their numerical accuracy.

In Table 2 we report the impact on the coefficients $\omega_{1}$ and $\omega_{2}$ of a regression analysis of the simulated data at different levels of inflation. The reported results are the average from 250 simulations of reported residual income on the lagged 
Table 2. The Impact of Inflation on Linear Dynamics (depreciation rate $=15 \%$ )

\begin{tabular}{lccccc}
\hline Inflation & $\omega_{1}$ & $t$-value & $\omega_{2}$ & $t$-value & Theoretical $\omega_{2}$ \\
\hline $0 \%$ & 0.574 & 7.12 & 0.0002 & 0.07 & 0.0000 \\
$1 \%$ & 0.574 & 7.02 & 0.0029 & 0.86 & 0.0025 \\
$2 \%$ & 0.575 & 6.92 & 0.0051 & 1.40 & 0.0046 \\
$3 \%$ & 0.575 & 6.82 & 0.0068 & 1.76 & 0.0062 \\
$4 \%$ & 0.574 & 6.71 & 0.0081 & 1.97 & 0.0074 \\
$5 \%$ & 0.575 & 6.64 & 0.0088 & 2.05 & 0.0081 \\
$6 \%$ & 0.575 & 6.55 & 0.0091 & 2.04 & 0.0084 \\
$7 \%$ & 0.575 & 6.46 & 0.0089 & 1.94 & 0.0081 \\
$8 \%$ & 0.575 & 6.37 & 0.0082 & 1.75 & 0.0075 \\
$9 \%$ & 0.575 & 6.30 & 0.0070 & 1.46 & 0.0063 \\
\hline
\end{tabular}

The table shows how inflation affects the estimation coefficients and $t$-values in the regression models based on a single lag for both residual income and book value: $x_{t+1}^{h c}=\omega_{1} x_{t}^{h c}+\omega_{2} b_{t}^{h c}+\varepsilon_{t+1}$. The averages are based on the average of 250 independent estimates with a sample size of 150 for each regression, assuming a $15 \%$ rate of depreciation. The final column shows the theoretical value calculated from equation (10) assuming $\omega_{1}=0.6$ and the rate of inflation and depreciation as above.

values of reported residual income and reported equity book values. We assume inflation rates change from $0 \%$ up to $9 \%$ and a depreciation rate of $15 \%$. We also compute the theoretical values displayed in the final column of Table 2, where in order to gain the required degree of accuracy in this example we used 150 observations in the regression.

Again it can be seen that while the coefficient of $\omega_{1}$ is constant and not significantly different from its input value of 0.6 , both the coefficient of $\omega_{2}$ and its significance depends on the rate of inflation. At inflation rates of more than $2 \%$ this term becomes statistically significant. It should be noted that this statistical significance is achieved in the controlled environment of a simulation model. Hence, whether such a positive coefficient can be observed in real data sets is a moot point, with empirical evidence mainly of a contradictory nature (Choi et al., 2006; Dechow et al., 1998; Myers, 1999). Nonetheless, in our case, although the coefficient of $\omega_{2}$ is small and only just statistically significant at the $10 \%$ level, its impact on valuation is highly significant, as we shall shortly see. The simulation model also provides further insights into the long run nature of the results. For example when we average the growth in book values we find that although year-on-year growth is highly variable, over the long run the average growth in book values is approximately equal to one plus the rate of inflation. For example, at an inflation rate of 5\%, the median growth rate observed is $5.2 \%$. However the inter-quartile range is $-4.5 \%$ to $16.8 \%$. This seems comparable with much historical data and makes growth estimates for individual firms using empirical data fraught with difficulties.

\subsection{Valuation and Inflation}

We have discussed how the Ohlson model may be modified in the presence of inflation and developed a closed form theoretical model of the valuation 
weights. However, in developing this closed form model, a number of simplifying assumptions had to be made. The principal purpose for building a simulation model is to explore the numerical accuracy of the various approaches to equity valuation using historical cost data in the presence of an inflationary environment. In the case of valuation, we use the simulation model for two purposes. The first is for a comparison of the overall accuracy of the different valuation models that we discuss. The second is to explore the accuracy of the theoretical modelling of the parametric representation of the valuation weights under inflation, as set out in equation (16). The results of these explorations are reported in Tables 3 and 4.

In Table 3, we report the results of our investigations, where we consider four valuation models. The first of these is the Ohlson (1995) residual income valuation model (Model 1 in Table 3). Model 2 is a limited-horizon model, where we include five years of residual income in the valuation prior to implementing a horizon value, using the Ohlson model at that date to take account of all subsequent residual incomes. This enables us to compare the impact of superior forecasts against superior modelling. We also explore the impact of parameterization using the matrix approach (Model 3) as per equation (18). The final model (Model 4 of Table 3) that we examine is the theoretical model as set out in equations (15) or (16). Again, for each model, we estimate the relevant parameters using OLS regressions from our simulated data over periods $t=51$ to 80 , effectively 30 years of data. We then compute the value-to-price ratio, $\left(V_{t}-P_{t}\right) / P_{t}$, where the valuation is made at $t=80$. Here, $P_{t}$ is calculated from the dividend discount model over a 500 period horizon and the intrinsic values $V_{t}$ are calculated substituting the parameter estimates from the regressions into each of the valuation models. In constructing Table 3 , we assume the following input values, a depreciation rate of $15 \%$, a real cost of capital of $6.6 \%$ and an assumed persistence of abnormal earnings, $\omega=0.6$.

The first line of Table 3 at each rate of inflation, shows the under- or overvaluation. These reported values represent the averages of 250 independent simulations. We note that the models 1 and 2 exhibit substantial undervaluation, when using historical accounting information and that this occurs even under mildly inflationary conditions. In contrast, we note that models 3 and 4, which incorporate a mechanism for adjusting for the conservatism inherent in historical accounting data, perform considerably better in terms of the size of the error in valuation, with the errors in our theoretical model being at worst about $4 \%$. From this, we infer that ignoring the book value term in the linear information dynamics leads to a severe under-valuation in the corresponding valuation model. Hence, although our prior investigations suggest that the coefficient in the linear dynamics of lagged book value is small, it makes a substantial contribution to the valuation process.

Table 3 also shows the Vuong Z-statistic derived from a comparison of the models. A positive value implies the superiority of the model in the row, whereas a negative value indicates the superiority of the model in the column. 
Table 3. A comparison of the valuation models

\begin{tabular}{|c|c|c|c|c|c|c|}
\hline Inflation & & & Model 1 & Model 2 & Model 3 & Model 4 \\
\hline & Valuation Error & & $3.3 \%$ & $-12.3 \%$ & $0.5 \%$ & $3.0 \%$ \\
\hline & R-squared & & $3.2 \%$ & $44.4 \%$ & $3.9 \%$ & $4.2 \%$ \\
\hline \multirow[t]{5}{*}{$0 \%$} & Model 1 & & & -6.41 & 4.60 & 4.60 \\
\hline & Model 2 & Vuong-Z & & & 7.76 & 6.13 \\
\hline & Model 3 & & & & & -4.75 \\
\hline & Valuation Error & & $-2.0 \%$ & $-17.1 \%$ & $-1.2 \%$ & $3.1 \%$ \\
\hline & R-squared & & $2.9 \%$ & $44.0 \%$ & $3.6 \%$ & $4.1 \%$ \\
\hline \multirow[t]{5}{*}{$1 \%$} & Model 1 & & & -6.94 & 4.16 & 4.16 \\
\hline & Model 2 & Vuong-Z & & & 7.92 & 6.48 \\
\hline & Model 3 & & & & & -4.39 \\
\hline & Valuation Error & & $-6.9 \%$ & $-21.6 \%$ & $-2.0 \%$ & $2.7 \%$ \\
\hline & R-squared & & $2.6 \%$ & $43.5 \%$ & $3.4 \%$ & $4.0 \%$ \\
\hline \multirow[t]{5}{*}{$2 \%$} & Model 1 & & & -7.21 & 3.43 & 3.43 \\
\hline & Model 2 & Vuong-Z & & & 7.71 & 6.02 \\
\hline & Model 3 & & & & & -4.18 \\
\hline & Valuation Error & & $-11.3 \%$ & $-24.9 \%$ & $-4.0 \%$ & $2.8 \%$ \\
\hline & R-squared & & $2.3 \%$ & $42.8 \%$ & $3.2 \%$ & $3.9 \%$ \\
\hline \multirow[t]{5}{*}{$3 \%$} & Model 1 & & & -7.30 & 2.36 & 2.36 \\
\hline & Model 2 & Vuong-Z & & & 7.18 & 5.10 \\
\hline & Model 3 & & & & & -4.06 \\
\hline & Valuation Error & & $-16.1 \%$ & $-27.5 \%$ & $-6.2 \%$ & $1.9 \%$ \\
\hline & R-squared & & $1.8 \%$ & $41.7 \%$ & $3.0 \%$ & $3.8 \%$ \\
\hline \multirow[t]{5}{*}{$4 \%$} & Model 1 & & & -7.04 & 0.82 & 0.82 \\
\hline & Model 2 & Vuong-Z & & & 6.34 & 3.93 \\
\hline & Model 3 & & & & & -4.00 \\
\hline & Valuation Error & & $-20.1 \%$ & $-30.6 \%$ & $-8.1 \%$ & $1.9 \%$ \\
\hline & R-squared & & $1.4 \%$ & $39.6 \%$ & $2.8 \%$ & $3.8 \%$ \\
\hline \multirow[t]{5}{*}{$5 \%$} & Model 1 & & & -5.29 & -0.74 & -0.74 \\
\hline & Model 2 & Vuong-Z & & & 5.00 & 2.49 \\
\hline & Model 3 & & & & & -3.96 \\
\hline & Valuation Error & & $-23.3 \%$ & $-34.1 \%$ & $-9.9 \%$ & $1.8 \%$ \\
\hline & R-squared & & $0.9 \%$ & $34.8 \%$ & $2.6 \%$ & $3.7 \%$ \\
\hline \multirow[t]{5}{*}{$6 \%$} & Model 1 & & & -2.62 & -1.26 & -1.26 \\
\hline & Model 2 & Vuong-Z & & & 2.39 & 0.58 \\
\hline & Model 3 & & & & & -3.94 \\
\hline & Valuation Error & & $-26.2 \%$ & $-37.6 \%$ & $-10.6 \%$ & $1.6 \%$ \\
\hline & R-squared & & $0.3 \%$ & $17.6 \%$ & $2.5 \%$ & $3.6 \%$ \\
\hline \multirow[t]{5}{*}{$7 \%$} & Model 1 & & & -1.22 & -1.10 & -1.10 \\
\hline & Model 2 & Vuong-Z & & & -0.48 & -0.82 \\
\hline & Model 3 & & & & & -3.92 \\
\hline & Valuation Error & & $-29.0 \%$ & $-40.8 \%$ & $-10.4 \%$ & $1.5 \%$ \\
\hline & R-squared & & $0.0 \%$ & $7.9 \%$ & $2.3 \%$ & $3.5 \%$ \\
\hline \multirow[t]{5}{*}{$8 \%$} & Model 1 & & & -1.11 & -1.07 & -1.07 \\
\hline & Model 2 & Vuong-Z & & & -0.85 & -0.98 \\
\hline & Model 3 & & & & & -3.92 \\
\hline & Valuation Error & & $-31.5 \%$ & $-43.5 \%$ & $-11.0 \%$ & $1.4 \%$ \\
\hline & R-squared & & $0.3 \%$ & $22.3 \%$ & $2.2 \%$ & $3.5 \%$ \\
\hline
\end{tabular}


Table 3. Continued

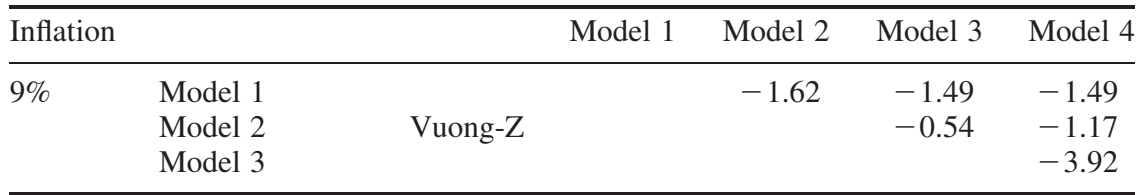

The table shows the under- or over-valuation resulting from a comparison of intrinsic value-to-price measured over periods $t=50$ to 80 as measured by $\left(V_{t}-P_{t}\right) / P_{t}$, where $P_{t}$ is calculated from the dividend discount model over a 500 period horizon and intrinsic values $V_{t}$ are computed according to one of the following four appropriately parameterized valuation models. The table also shows the Vuong Z-statistic derived from a comparison of the models. A positive value implies the superiority of the model in the row, whereas a negative value indicates the superiority of the model in the column. The assumed depreciation rate is $15 \%$, real cost of capital is $6.6 \%$ and the assumed persistence of abnormal earnings is $\omega=0.6$. The reported values are the averages of 250 independent simulations.

Model 1: $V_{t}=b_{t}+\frac{\omega x_{t}}{(1+i-\omega)}$

Model 2: $V_{t}=b_{t}+\frac{x_{t+1}}{1+i}+\frac{x_{t+2}}{(1+i)^{2}}+\frac{x_{t+3}}{(1+i)^{3}}+\frac{x_{t+4}}{(1+i)^{4}}+\frac{x_{t+5}}{(1+i)^{5}}+\frac{\omega x_{t+5}}{(1+i)^{5}(1+i-\omega)}$

Model 3: $V_{t}=b_{t}+(0,1,0)[(1+i) \mathbf{I}-\boldsymbol{\Omega}]^{-1}[\boldsymbol{\Omega}] \mathbf{z}_{t}$

Model 4: $V_{t}=(1-k) b_{t}+k\left(\varphi e_{t}-d_{t}\right)$ where

$k=i \theta-(1+i) \psi$,

$\varphi=\frac{(1+i)(\theta-\psi)}{i \theta-(1+i) \psi}$

$\theta=\frac{\omega}{(1+i-\omega)}$ and

$\psi=\frac{\eta(1-\alpha)}{\alpha(1+\eta)} \frac{(1+\eta-\omega)}{(1+i-\omega)}$.

This provides important insights into the modelling process. The key point to note is that according to this statistic at relatively low levels of inflation, i.e. not exceeding 5\%, model 2 clearly dominates the other models, despite its consistent undervaluation. This model incorporates an additional five years of data on observed residual income, yielding effectively perfect forecasts of the future earnings over that period. However, at higher levels of inflation, our parameterized theoretical model dominates. The reason for this apparent anomaly becomes obvious when we examine the square of the correlation coefficient, between the valuation model and the discounted dividend price. This is shown in the second line of Table 3 at each rate of inflation. The square of the correlation between the 'true' valuation and that generated by model 2 is of the order of $40 \%$. In contrast, the corresponding value for models 3 and 4 is only about $3 \%$ to $4 \%$. Thus, despite their greater accuracy in terms of bias, the ability of models 3 and 4 to track individual companies is quite poor. This low value for the correlation coefficient arises because of the considerable uncertainties in parameter estimates, to which the models are quite sensitive. This can be explained as follows. Models 1, 3 and 4 all try to derive a value for a firm, with a presumed infinite life by observing just three accounting variables at a particular point in time, where 
the path of these variables is highly stochastic. ${ }^{11}$ In contrast, model 2 uses 5 years of perfect forecasts to generate the valuation. Although this valuation is biased it tracks the 'true' value more closely.

Using our simulation model we are able to explore a number of other scenarios. Consistent with the arguments presented for equations (12) and (13), we assume that future growth in the 5-year horizon model 2 takes place at the rate of inflation, assuming zero real growth. This results in small overvaluations in the extended 5-year horizon model (Model 2) of 7.8\% at zero inflation and 4.6\% at an inflation rate of $9 \%$. However, the uncertainty in future growth reduces the square of the correlation coefficient between actual and intrinsic valuation to around $33 \%$. We also carried out simulation runs by setting nominal growth equal to the inflation rate plus an assumed real GDP growth of $2.5 \%$. This appeared not to make any material differences to the conclusion already reached and details are not reported. In the simulation, investment and book values are stochastically related with both growing at an average rate in line with inflation. Therefore, we also try the effect of making investment at time $t$ dependent of time-t earnings. In effect, this imposes a dividend policy on the firm via retentions. We find that its main impact is to increase the tracking ability of model 3 , which formally incorporates a model of dividend policy ${ }^{12}$ and hence its performance relative to the other models.

We next explore the impact of the interaction between depreciation rates and the rate of inflation on the standard Ohlson (1995) model, in which we assume that residual income follows a simple autoregressive process, effectively ignoring any book value term in the information dynamics. The results of this interaction are illustrated in Figure 1. The undervaluation decreases with increasing depreciation since the average age of asset values is less. Even then at relatively low rates of inflation we see that there is a considerable under-valuation resulting from the use of a residual income model with an assumed simple autoregressive process for abnormal earnings. Interestingly, over the period Dechow et al. (1998) tested the

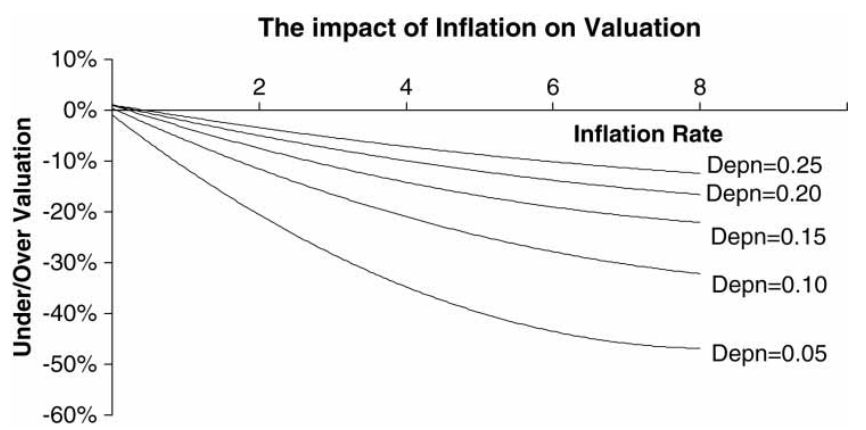

Figure 1. The impact of valuation on inflation. The figure illustrates the undervaluation under historical cost accounting using a residual income model for valuation assuming that abnormal earnings follow a simple autoregressive process. 
Ohlson model, the rate of inflation averaged 5.4\%. At a rough estimate of US median depreciation rates of $13 \%$, one might expect an undervaluation of the order of $25 \%$. Dechow et al. actually observed an undervaluation somewhat greater than this. We do not claim that inflation is the sole factor in undervaluation in RIVM but simply that it can be a major contributory factor.

Finally we use the output from our simulation model to check the accuracy of the theoretical weights in equation (16) where price is expressed as a linear combination of book value, earnings and dividends. We use the OLS model as in equation (22), scaling the time series data by opening book-values to reduce heteroscedasticity for this test.

$$
P_{t}-b_{t}=\alpha b_{t}+\beta e_{t}+\delta d_{t}+\varepsilon_{t}
$$

As a preliminary, we first test the dividend displacement constraint that $\alpha=\delta$. We find that $\alpha$ and $\delta$ are indeed indistinguishable at a high level of significance $(0.1 \%)$, and we do not provide further details of this test. Instead, we concentrate on the coefficients in the restricted regression with $\alpha=\delta$. We display the results of our investigation in Table 4 . Table 4 shows the theoretical values of the coefficients of $\alpha(=\delta)$ and $\beta$, derived from equation (16) together with their corresponding OLS estimates. The predicted and observed values follow the same monotonic trends. The reported $t$-statistics show the significance of the differences between the theoretical and estimated coefficients. We also note that all these differences are statistically insignificant. This offers some support to the robustness and accuracy of the numerical approximations used in the closed form model given by equation (16). However, we note that only at relatively high levels of inflation are our estimated coefficients different from zero, and only then for the book value terms. Interestingly, we predict and observe a positive weight attached to dividends at inflation rates greater than $2 \%$. Thus, we see that the use of historical cost accounting in an inflationary environment may explain one of the puzzles emerging from empirical regression studies of the determinants of goodwill, where a positive, rather than the hitherto expected negative, coefficient for dividends is both predicted and observed (Ashton and Wang, 2008; Clubb, 1996; Hand and Landsman, 2005; Rees, 1997).

It would be disingenuous not to remark that, despite our estimations being based on a time-series average of 250 independent simulations, each consisting of 30 periods in a controlled environment, the precision as measured by our standard errors is relatively poor. While the average value of the computed coefficients are in close agreement with their theoretical counterparts, it is clear from the relative size of the implied standard errors that individual runs must show a substantial variation. A careful inspection of the coefficients in the 250 independent simulations confirmed this to be so. Such an observation may not bode well for empirical investigators within the much more restricted confines imposed by real data. 
Table 4. A comparison of theoretical and observed regression coefficients

\begin{tabular}{|c|c|c|c|c|c|c|c|c|c|c|}
\hline Rate of inflation & $0 \%$ & $1 \%$ & $2 \%$ & $3 \%$ & $4 \%$ & $5 \%$ & $6 \%$ & $7 \%$ & $8 \%$ & $9 \%$ \\
\hline \multicolumn{11}{|l|}{ Book/dividends $(\alpha=\delta)$} \\
\hline Theoretical Coefficient & -0.08 & -0.04 & 0.00 & 0.04 & 0.08 & 0.12 & 0.17 & 0.21 & 0.26 & 0.30 \\
\hline Observed Coefficient & -0.05 & 0.00 & 0.05 & 0.10 & 0.15 & 0.20 & 0.25 & 0.30 & 0.35 & 0.40 \\
\hline T-value of Difference & -0.55 & -0.54 & -0.54 & -0.53 & -0.52 & -0.50 & -0.49 & -0.48 & -0.47 & -0.46 \\
\hline T-value of Observed & -0.65 & 0.02 & 0.50 & 0.86 & 1.13 & 1.34 & 1.51 & 1.65 & 1.77 & 1.87 \\
\hline \multicolumn{11}{|l|}{ Earnings $(\beta)$} \\
\hline Theoretical Coefficient & 1.37 & 1.30 & 1.23 & 1.17 & 1.10 & 1.03 & 0.96 & 0.90 & 0.83 & 0.77 \\
\hline Observed Coefficient & 0.75 & 0.68 & 0.62 & 0.55 & 0.49 & 0.42 & 0.36 & 0.29 & 0.23 & 0.17 \\
\hline T-value of Difference & -0.51 & -1.14 & -1.17 & -1.14 & -1.11 & -1.07 & -1.03 & -1.00 & -0.97 & -0.94 \\
\hline T-value of Observed & 0.61 & 1.26 & 1.16 & 1.02 & 0.88 & 0.74 & 0.61 & 0.49 & 0.37 & 0.26 \\
\hline $\mathrm{R}^{2}$ & 0.34 & 0.50 & 0.58 & 0.65 & 0.70 & 0.73 & 0.75 & 0.76 & 0.77 & 0.78 \\
\hline
\end{tabular}

The table shows the estimated coefficients from the restricted regression equation $P_{t}-b_{t}=\alpha b_{t}+\beta e_{t}+\delta d_{t}+\varepsilon_{t}$ with $\alpha=\delta$. The times series data is scaled by opening book values. The reported $t$-statistics are measures of the differences between the theoretical and observed coefficients. 


\section{Conclusion}

In this paper, we have explored theoretically, and numerically by simulation, the implications of historical cost accounting under inflationary conditions on residual income valuation models. We find that inflation does not affect the structure of the residual income model but rather distorts autoregressive information dynamics. We conjecture and establish that it is sufficient to correct for the impact of inflation by adding a positive weight associated with the inflation level to the book value term in the autoregressive relationship of residual income generation. Our analysis also indicates that substantial undervaluation can result in the use of historical cost data even under a moderate inflationary environment and we hypothesize that this may be one of the causes of undervaluation observed in simple residual income models for valuation. Both our theory and the numerical simulation again draw attention to the pivotal role of book value in residual income valuation models.

The present value of expected future abnormal earnings cannot bridge the gap between book value and market value when there is moderate inflation. The simulation model supported by theoretical analysis also suggests a way forward in such approaches to equity valuation. Thus, we show that if we adjust for understated book values then historical cost accounting should in theory give the reliable results. We also present an ad hoc valuation procedure that generalizes the autoregressive process into a vector autoregressive process, without making inflation adjustments to the accounts. Although these models work well within the context of the current controlled simulation environment, we draw attention to the fact that although these models are effective in removing bias they still produce relatively unreliable estimates of values for individual firms. This is because of the difficulty in estimating parameter values from the relatively short histories of individual firms and the problem of accurately predicting future growth in earnings. Even within a controlled environment and effectively homogeneous set of firms the standard errors of our estimated coefficients are relatively large. Nevertheless, we believe our paper provides insights into the practical problems facing empirical researchers and investment practitioners.

\section{Acknowledgements}

The authors acknowledge many helpful comments received from participants from AAA, EAA and BAA annual meetings, Manchester University, Bristol University, Lancaster University, Loughborough University and Imperial College London on early versions of the paper. The authors are also grateful for very helpful comments and suggestions from two anonymous reviewers.

\section{Appendix. Linear Information Dynamics under Inflation and Current Cost Accounting}

In this appendix we confirm that given consistent current cost accounting there is no distortion of the simple linear dynamics employed in our model setup. Our 
accounting focuses on the triple $\left\{b_{t}^{0}, x_{t}^{0}, d_{t}^{0}\right\}$ which represent book value of equity, abnormal earnings and dividends respectively at time $t$ under the assumption of a zero-rate of inflation, denoted by the 0 superscripts on the variables.

We write our linear dynamics in the form

$$
\mathbf{z}_{t+1}^{0} \equiv\left(\begin{array}{c}
b_{t+1}^{0} \\
x_{t+1}^{0} \\
d_{t+1}^{0}
\end{array}\right)=\boldsymbol{\Omega} \mathbf{z}_{t}^{0}+\varepsilon_{t+1}^{0}
$$

where the $\Omega$-matrix relates the expected value of the accounting variables to their value in the previous year. ${ }^{13}$

The corresponding cash triple is $\left\{Y_{t}^{0}, I_{t}^{0}, d_{t}^{0}\right\}$ where $Y_{t}^{0}$ is the cash inflow from operations in time $t, I_{t}^{0}$ is the investment cash flow, assumed to be linked by a cash balance equation $Y_{t}^{0}=I_{t}^{0}+d_{t}^{0}$.

The cash flow and accounting variables (in the absence of inflation) are connected as follows:

$$
\begin{aligned}
b_{t}^{0} & =(1-\alpha) b_{t-1}^{0}+I_{t}^{0} \\
x_{t}^{0} & =Y_{t}^{0}-(\alpha+i) b_{t-1}^{0}
\end{aligned}
$$

Here, $i$ denotes the nominal cost of capital, $\alpha$ the (accounting and economic) depreciation rate and $r$ the real cost of capital consistent with the relationship $1+i=(1+r)(1+\eta)$. Under a uniform rate of inflation $\eta$ and using current cost accounting we need to modify these equations. We recognize the increased depreciation charge and a holding gain in our measures of income. For simplicity, we assume physical and accounting depreciation coincide. Thus, we have

$$
\begin{gathered}
b_{t}^{c c}=b_{t-1}^{c c}-\alpha b_{t-1}^{c c}(1+\eta)+\eta b_{t-1}^{c c}+I_{t}^{0}(1+\eta)^{t} \\
=(1-\alpha)(1+\eta) b_{t-1}^{c c}+I_{t}^{0}(1+\eta)^{t} \\
x_{t}^{c c}=Y_{t}^{0}(1+\eta)^{t}-\alpha b_{t-1}^{c c}(1+\eta)+\eta b_{t-1}^{c c}-(R-1) b_{t-1}^{c c} \\
=Y_{t}^{o}(1+\eta)^{t}-(1+\eta)(\alpha+r-1) b_{t-1}^{c c}
\end{gathered}
$$

We can rewrite the above equations in terms of a lag operator where $L$ is a lag operator such that and $L b_{t}=b_{t-1}$ and $L^{2} b_{t}=b_{t-2}$ :

$$
\begin{gathered}
{[1-(1-\alpha)(1+\eta) L] b_{t}^{c c}=I_{t}^{0}(1+\eta)^{t}} \\
x_{t}^{c c}=Y_{t}^{0}(1+\eta)^{t}-(1+\eta)(\alpha+r-1) L b_{t}^{c c}
\end{gathered}
$$

By using equations (A2) and (A6), we deduce:

$$
\frac{b_{t}^{c c}}{(1+\eta)^{t}}=(1-(1-\alpha) L)^{-1} I_{t}^{0}=b_{t}^{0}
$$


from which equation (A9) follows:

$$
\frac{x_{t}^{c c}}{(1+\eta)^{t}}=Y_{t}^{0}-(\alpha+r-1) \frac{b_{t-1}^{c c}}{(1+\eta)^{t-1}}=x_{t}^{0}
$$

and trivially, since we are treating dividends as a cash flow, we have $\frac{d_{t}^{c c}}{(1+\eta)^{t}}=d_{t}^{0}$.

The importance of these observations is that the linear dynamics for current cost accounting can be written as

$$
E_{t}\left[\mathbf{z}_{t+1}^{c c}\right]=E_{t}\left[(1+\eta)^{t+1}\left(\begin{array}{c}
d_{t+1}^{0} \\
x_{t+1}^{0} \\
b_{t+1}^{0}
\end{array}\right)\right]=(1+\eta)^{t} \boldsymbol{\Omega} \mathbf{z}_{t}^{0}=\mathbf{\Omega} \mathbf{z}_{t}^{c c}
$$

Thus, any linear dynamics relationship is preserved under current cost accounting. In particular, if real residual income goes to zero then so does current cost residual income.

\section{Notes}

${ }^{1}$ Historical cost accounting ignores the increased depreciation charge associated with the nominal increase in value of assets but this overstatement of earnings is more than offset by excluding the holding gains implicit in clean surplus accounting.

${ }^{2}$ An 'other information' variable, also assumed to follow a simple dampening process, is introduced in Ohlson (1995). By definition, 'other information' has not been embedded in the current accounting variables. Estimation of 'other information' relies on forecasted future earnings. Consistent with the main body of empirical literature, we do not address this aspect of other information. Our focus here is on other accounting information not reflected in current abnormal earnings and book value and its role in predicting future abnormal earnings. We could easily extend the analysis to include an Ohlson-type other information variable, but do not do so in order to avoid complicating the picture unnecessarily.

${ }^{3}$ Under the clean surplus accounting rule, dividend-adjusted earnings are added to shareholder's book value, i.e. $b_{t}=b_{t-1}+e_{t}-d_{t}$ in both accounting systems. Ohlson (1999) points out that one can think of earnings in this identity as including any dirty surplus items that have bypassed the 'official' income statement.

${ }^{4}$ Our analysis holds if we assume the information dynamics of inflation follows a mean-reverting process, as per Hughes et al. (2004), and that the current inflation rate is equal to the long-run unconditional mean of inflation. In our subsequent simulation model, $\eta$ assumes a stochastic form.

${ }^{5}$ To do so in practice one would require, of course, that the firm had been in existence an infinitely long period of time.

${ }^{6} \mathrm{We}$ note that this assumption is consistent with our asymptotic growth result in equation (9). We explore this assumption in more detail later in the paper when we consider horizon valuation.

${ }^{7}$ This more complex structure under historical cost accounting contrasts sharply with the simple diagonal structure in the appendix under current cost accounting.

${ }^{8}$ This ensures that the initial condition for each simulation run is different since it is based on a random return on book equity, which itself is created by an accumulation of random investments. Any memory of the opening values at time $t=1$ is effectively lost.

${ }^{9}$ The real cost of capital is a compromise between various estimates assuming a real risk premium of $4.2 \%$ (Claus and Thomas, 2001; Fama and French, 2002) and an average real 
return on government debt of $2.4 \%$ (Ibbotson and Sinquefield, 2004). Its exact value is not crucial to our discussion.

${ }^{10} \mathrm{We}$ explore up to four lags; however we consistently find that only the first lag of residual income and book value is significant. Indeed, when we increase the number of lags of book value the statistical significance of all the lags disappears.

${ }^{11}$ When we set the uncertainty parameter $\sigma$ used in the generation of residual income to 0.033 , i.e. one-tenth of the value used in the reported simulations, the Vuong statistic shows that model 3 and 4 are superior, as evidenced by a double digit Vuong-Z statistic relative to model 2. However the corresponding standard deviation of return on equity is less that $2 \%$ p.a., a level of stability achieved by only a few companies.

${ }^{12}$ Of course, within our simulation, we have the advantage of a controlled stable environment and a long time series of accounting data with which to parameterize the model. Whether such a methodology is useful in practice remains to be seen. The simulation approach merely confirms that such an approach cannot be rejected out of hand.

${ }^{13}$ The random disturbance term $\epsilon$ is included in equation (A1) to reflect the fact that accounting variables are not simple deterministic functions of past values.

\section{References}

Ashton, D. and Wang, P. (2008) Valuation weights and accounting conservatism. Available at SSRN: http://ssrn.com/abstract=988680

Beaver, W. and Ryan, S. (2005) Conditional and unconditional conservatism: concepts and modeling, Review of Accounting Studies, 10, pp. 269-309.

Choi, Y-S, O'Hanlon, J. and Pope, P. (2006) Conservative accounting and linear information valuation models, Contemporary Accounting Research, 23(1), pp. 73-101.

Claus, J. and Thomas, J. (2001) Equity premia as low as three percent? Evidence from analysts' earnings forecasts for Domestic and International Stock Markets, Journal of Finance, 56, pp. $1629-1666$.

Clubb, C. (1996) Valuation and clean surplus accounting: some implications of the Feltham and Ohlson model for the relative information content of earnings and cash flows, Contemporary Accounting Research, 13, pp. 329-337.

Dechow, P. M., Hutton, A. P. and Sloan, R. G. (1999) An empirical assessment of the residual income valuation model, Journal of Accounting and Economics, 26, pp. 1-34.

Fama, E. and French, K. (2002) The Equity premium, Journal of Finance, 57, pp. 637-659.

Feltham, G. and Ohlson, J. (1995) Valuation and clean surplus accounting for operating and financial activities, Contemporary Accounting Research, 11, pp. 689-732.

Feltham, G. and Ohlson, J. (1996) Uncertainty resolution and the theory of depreciation measurement, Journal of Accounting Research, 34, pp. 209-234.

Feyr, E. and Tyran, J. R. (2001) Does money illusion matter? American Economic Review, 91, pp. 1239-1262.

Gregory, A., Saleh, W. and Tucker, J. (2005) A UK test of an inflation-adjusted Ohlson model, Journal of Business Finance and Accounting, April/May, pp. 487-534.

Hand, J. and Landsman, W. (2005) The pricing of dividends in equity valuation, Journal of Business Finance and Accounting, 32, pp. 435-469.

Ibbotson, R. G. and Sinquefield, R. A. (2004) Stocks, Bonds, Bills and Inflation (Chicago: Yearbook).

Hughes, J., Li, J. and Zhang, M. (2004) Valuation and accounting for inflation and foreign exchange, Journal of Accounting Research, 42(4), pp. 731-754.

Miller, M. and Modigliani, F. (1961) Dividend policy, growth and the valuation of shares, Journal of Business, 34, pp. 411-433.

Myers, J. (1999) Implementing residual income valuation with linear information dynamics, The Accounting Review, 74, pp. 1-28. 
Modigliani, F. and Cohn, R. (1979) Inflation, rational valuation and the market, Financial Analysts Journal, 35, pp. 24-44.

O'Hanlon, J. and Peasnell, K. (2004) Residual income valuation: are inflation adjustments necessary? Review of Accounting Studies, 9, pp. 375-398.

Ohlson, J. (1995) Earnings, book values, and dividends in security valuation, Contemporary Accounting Research, 11, pp. 661-687.

Ohlson, J. (1999) On transitory earnings, Review of Accounting Studies, 4, pp. 145-162.

Ohlson, J. and Juettner-Nauroth, B. (2005) Expected EPS and EPS growth as determinants of value, Review of Accounting Studies, 10, pp. 349-365.

Rees, W. P. (1997) The impact of dividends, debt and investment on valuation models, Journal of Business Finance and Accounting, pp. 1111-1140.

Ritter, J. R. and Warr, R. S. (2002) The decline of inflation and the bull market of 1982-1999, Journal of Financial and Quantitative Analysis, 37, p. 1.

Watts, R. (2003a) Conservatism in accounting part I: explanations and implications, Accounting Horizons, 17, pp. 207-221.

Watts, R. (2003b) Conservatism in accounting part II: evidence and research opportunities, Accounting Horizons, 17, pp. 287-301. 